\title{
COUNTER-GOVERNANCE AND 'POST-EVENT PREVENT': REGULATING RUMOURS, FAKE NEWS AND CONSPIRACY THEORIES IN THE AFTERMATH OF TERROR
}

\author{
Martin Innes, Bethan Davies and Trudy Lowe \\ Cardiff University Crime and Security Research Institute \\ Friary House, Greyfriars Road, Cardiff CF10 3AE. UK \\ Corresponding Author: Martin Innes InnesM@cardiff.ac.uk
}

October 2019

\begin{abstract}
Framed by ongoing debates about both the legitimacy and efficacy of the UK government's Prevent counter-terrorism strategy, this article examines how and why it is resisted and contested in both overt and more nuanced ways. The analysis focuses specifically upon how such contests are manifested in the aftermath of terror events illuminated by two distinct data sources. These are empirical data collected from interviews with policy developers and deliverers, together with material derived from systematic monitoring and assessment of social media following four terror attacks in the UK in 2017. It is suggested that such incidents are singularly important moments because they simultaneously evidence the need for Prevent-type interventions, but also such interventions' apparent failures to stop such violence.
\end{abstract}

A key theme for the article concerns how, situated in the contemporary information environment, a key strand of Prevent work conducted in the wake of terrorist violence involves managing the potential impacts of rumours, conspiracy theories and other disinformation. The management of public perceptions and reputation thus emerge as vital undertakings. Insights from the data are used to develop a more conceptually oriented argument concerning the logics and rationalities of 'counter-governance', positioning it in a wider literature on de-centred governance and regulation.

Keywords: counter-governance; counter-terrorism; Prevent; rumour; conspiracy; disinformation 


\subsection{INTRODUCTION}

Since its inception following the 2005 bomb attacks in London, the UK's Prevent Strategy for countering violent extremism has been both commended and contested (Innes et al., 2017; Lakhani, 2012). Government, police, and a selection of other voices have cast it as an imperfect but necessary response, given the variety and intensity of extremist risks and threats. An alternative framing has been propagated by those who cast Prevent as a 'tainted brand', inducing a range of negative social and political impacts, most notably constructing all Muslims as a 'suspect community' (Kundani, 2009; Pantazis and Pemberton, 2009). The more scholarly accounts in this genre connect Prevent with deeper trajectories in the logics, rationalities and practices of governance (Ashworth and Zedner, 2014; O'Toole et al., 2016; Walker and McKay, 2015).

This article explores the evolution of these ideas in the immediate aftermath of significant terrorist attacks, rather than in 'ordinary time'. The post attack window is potentially instructive for any such debates, in that such moments simultaneously clarify the need for some preventative framework, albeit the violence enacted evidences that those measures have, in some sense, failed. Given how public attention tends to be captured by such events, the acts and interests of a relatively small number of citizens can potentially engage a much wider political and public constituency.

The specific contribution to knowledge focusing upon such moments affords is thus threefold. First, it contributes to a more nuanced and sophisticated evidence informed understanding of processes of social reaction to terrorism. Second, it enriches our insights about public perceptions of counter-terrorism generally and the status of Prevent specifically. Finally, at a deeper, more conceptual level, the discussion keys into how and why policy interventions intended to regulate collective behavior are resisted and subject to alternative framings.

The theoretical departure point for engaging with these themes is Bloomfield's (2013) 'counter-governance' construct. Although insightful in pointing to the influence of resistances and contests in shaping how governance happens in practice, exposure to the empirical data about reactions to terror events, suggests a need for an element of 're-tooling' and re-framing. Specifically, integrating elements of Bevir's (2016) conceptualisation of decentered governance identifies some rather more subtle and intricate instances of counter-governance.

A key innovation of the article is that in pursuing these themes, the discussion is informed by qualitative interview data with practitioners, blended with excerpts extracted from social media communications. This is an unusual combination inasmuch as previous studies in this area typically tend to be based upon one or other of these sources. The, qualitative interviews with Prevent practitioners and community members are used to explore a range of attitudes and perceptions towards Prevent in general terms. This frames a more focused mass observation, conducted through social media analytics, of empirical examples of counter-governance after the four 2017 UK terrorist attacks. Following Gonzalez-Bailon (2017) and Salganik (2017) amongst others, this latter analysis highlights how such new and innovative forms of data render perceptible dimensions of social processes that were hitherto difficult to observe. In this case, aspects of social reaction to terrorism that assist in understanding the contests played out about Prevent. Moreover, the multi-method approach underpinning this article is intended to reflect how the online and offline are increasingly interpolated in terms of shaping public responses to terrorism. 


\subsection{DATA AND METHOD}

In-depth, semi-structured qualitative interviews with nine Prevent practitioners and community members in the UK, were conducted in the 18 months prior to the 2017 UK terror attacks. Participants were sampled from two broad groups: policy developers and deliverers; and more 'grassroots' community representatives. Amongst the former, were Home Office Prevent Coordinators with over-arching responsibility for Prevent in their respective UK cities. They were involved in all aspects of Prevent delivery, including strategic direction, management of the 'Channel' de-radicalisation programme, practitioner and public awareness raising activities, and responses to critical incidents. Other participants were representatives from nongovernmental organisations which accessed Prevent funding for counter-extremist programmes, including training provision for local services such as schools and the NHS.

Additional interviews were conducted with individuals with a more 'hands-on' role in relation to Prevent. They were based in community organisations, mostly working as youth or community support. Some, but not all, of their projects received Prevent funding and thus the amount of direct work performed by the individuals in this arena varied. However, all had detailed understandings of Prevent policy and statutory duties, the work being done with communities on-the-ground, and the issues and challenges faced in this context.

These interview data provide an overview of the conduct of Prevent and some of the contemporary challenges it encounters, including how it is resisted and contested. Such insights are substantially supplemented and augmented by data collected via systematic monitoring of social media following four of the five terror attacks that occurred in the UK in the space of four months during 2017. Each of these events generated significant amounts of online public reaction, particularly on social media. Specifically of interest here, were a number of 'soft facts' shared online (Innes, 2014). Defined as rumours, conspiracy theories and disinformation, these attempted to counter aspects of both the work and legitimacy of the government and its agencies. Some communications were targeted directly at their responses to the attacks, whilst others were framed more generally. In effect, this second dataset takes some of the key themes identified through analysis of the interviews, to examine how they manifested in the febrile aftermath of terrorist attacks.

Across the four incidents, researchers had access to 45 million Twitter data points (original tweets and retweets), as well as other material collected manually across multiple other social media platforms (such as Facebook and YouTube). Twitter materials were systematically collected from the Twitter Streaming API at the time of the events, using the location-based hashtags that emerged from each one (e.g. \#westminster, \#londonbridge, \#manchester) as the collection terms. From this, a number of case studies were identified and subject to further qualitative analyses, which have informed the arguments presented herein. It is the "between method triangulation' of blending data from these two sources, that lends this article a particular perspective on how and why Prevent delivery is resisted and contested.

A sense of the relative distribution of the Twitter materials is provided by Figure 1. It is clear that, in terms of social media communication, the Manchester Arena attack dominated. This is likely attributable to the nature of the violence (bomb), the number of victims involved in the incident, and also potentially their young age (meaning they were heavy social media users). A valuable quality of social media as a data source relates to its streaming quality, together with its blend of high resolution and large volume. This enables the tracking and tracing of how events unfold and develop over time. 


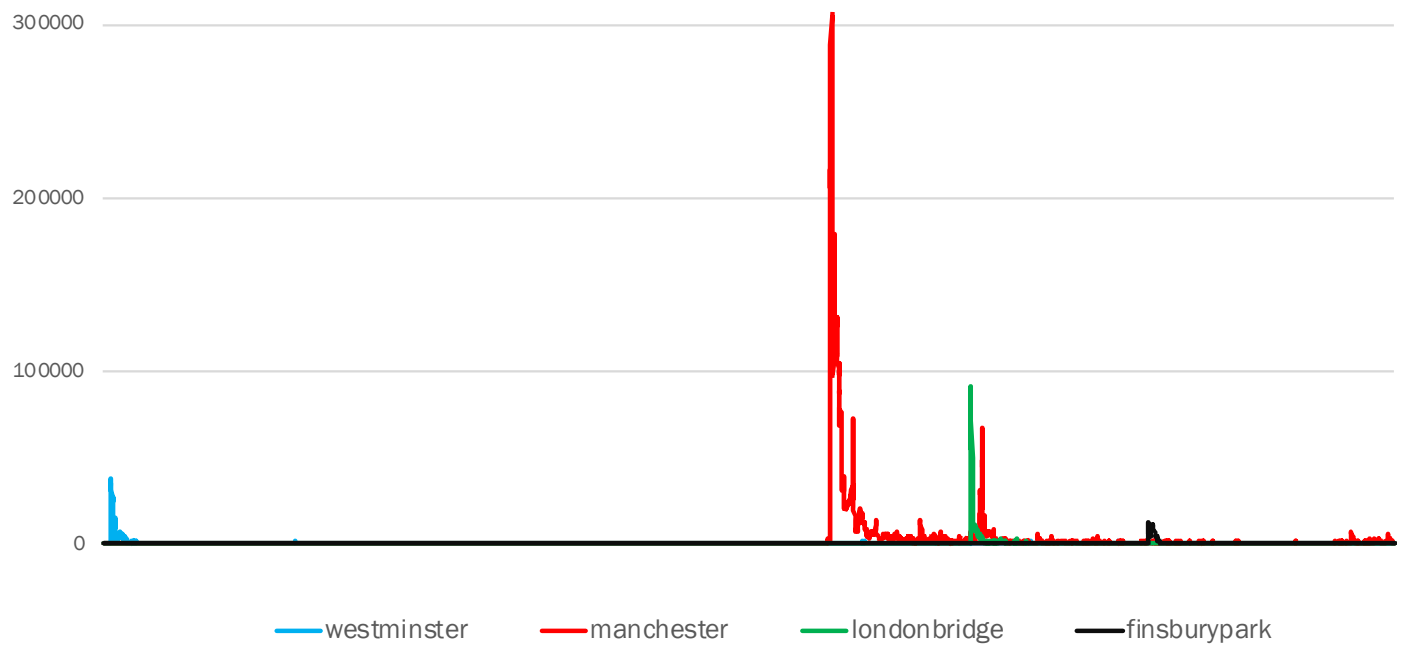

FIGURE 1: Distribution of Twitter data associated with terrorist attacks at Westminster, Manchester Arena, London Bridge and Finsbury Park, 2017

\subsection{PREVENT: POLICY DEVELOPMENT AND DELIVERY}

The UK government's cross-departmental CONTEST strategy was introduced in the mid2000s in recognition of the limitations exposed by the events of 09/11/01, the Madrid train bombings in 2004 and the 2005 London bombings. It has subsequently undergone a process of policy transfer to provide the basis of the European Union's policy framework. ${ }^{1}$ CONTEST is constructed around four key strands of activity (HM Government, 2009):

- Prepare - focuses upon ensuring processes and systems are in place in anticipation of a range of perceived threats. It addresses both cross-governmental responses, but also community resilience;

- Prevent - is designed to inhibit and interdict processes of violent radicalisation, and those who seek to propagate extremist ideas.

- Protect - involves a range of activities, often derived from the principles of situational crime prevention, seeking to reduce risks and threats to elements of the critical national infrastructure and crowded places. The idea being to minimise the opportunities for an attack and limit consequences should one occur.

- Pursue - is more in the traditions of police and security service involvement in counterterrorism work. It focuses upon identifying and securing motivated offenders.

\footnotetext{
${ }^{1}$ (Strasbourg: 14469/05, 2005) p 2. The Strategy is divided into the four pillars - Prevent, Protect, Pursue and Respond - a taxonomy very redolent of the UK version.
} 
Of the four strands of CONTEST, Prevent has been the most politically contentious and publicly debated. There have been repeated allegations that it is a governmental programme to 'spy' upon communities and has been profoundly alienating in terms of Muslim communities' relationships with the police and wider governmental apparatus (Kundani, 2009). Given such claims, it is of note that Prevent has been subject to two systematic revisions, first in 2008 and then in 2011. The former was triggered by a perception that insufficient attention had been paid to developing genuinely preventative modes of working and as a consequence CONTEST was overly reliant upon more established 'Pursue' practices. The revisions in 2011 were more explicitly ideologically motivated by a change in government the year before. The new coalition were of the view that where the previous iterations of Prevent focused upon integrating three key domains of: counter-radicalisation; de-radicalisation; and community cohesion building. They now desired a much clearer distinction between counter-terrorism, and activities addressing integration and cohesion (HM Government, 2011).

Coherent with this re-focusing, there was a move away from civil society and grassroots community groups being involved in the delivery of Prevent (Lakhani, 2012), to an accent upon the roles of public service providers, such as education, health and social services. This was further entrenched by the introduction of the statutory Prevent Duty in 2015 (HM Government, 2015). Throughout, Prevent has been repeatedly conceptualised as a form of governance. O'Toole et al (2016) argue that Prevent has most often been cast as a disciplinary mode of regulatory governance predicated upon the management of security risks via a preemptive approach focusing on the conduct of Muslims (see also Heath-Kelly, 2013). Birt (2008) noting this regulatory disposition, describes a range of mechanisms employed to 'discipline' Muslim subjects (e.g. trying to mobilise the entire Muslim community against extremism and promoting liberal Islam). In their empirical research, O'Toole et al (2016) found tensions between community cohesion principles and Prevent practices, which had often caused implementation problems, complicating any conception of Prevent as a purely disciplinary form of governance.

That revisions to Prevent have been necessary is indicative of how challenging it is to deliver counter-terrorism differently from established models and the issues that any such attempts necessarily turn up. Innes et al. (2011) examined the police role in Prevent. Contra the oft stated charge that the instigation of Prevent has functioned to alienate Muslim communities, opinion indicators from the British Crime Survey implied a more complex picture. Overall, they suggested people from Muslim faith backgrounds exhibit higher levels of trust and confidence in the police when compared with the general population. Young Muslim men had marginally more negative perceptions and attitudes than did their general population compatriots, but even then, nearly 4 out of 10 surveyed expressed positive views of policing.

In terms of how it is constructed in policy discourses, Prevent is quite clearly infused with the spirit of pre-emptive risk management and prediction common to many contemporary forms of governance. However, interviews with practitioners drew attention to more subtle modes of deployment, most notably where Prevent style interventions helped manage the community impacts of incidents when plots were alleged to have been uncovered and 'Pursue' counterterrorism interventions made. For example:

"I think the young people there, now, especially with the arrest this week have become highly vulnerable" (0004) 
"it stigmatised the whole community, it has put the community in a really bad way" (0001)

In both of these cases, the practitioners recognised the need for careful community impact management, and described how they were working to try and prevent the escalated community tensions developing into more serious problems.

A key concern for Prevent workers was how, following a significant terror event, extremists would try and capitalise on and exploit it to further their cause. Accordingly, preventative activity would be mobilized to try and inhibit any such influence. One case described a known extremist (a member of the proscribed group al-Muhajiroun) who was posting messages on Facebook, targeting young people. This was not the first time such online behaviour had been observed, and members of the local community had agreed they would collectively reply whenever it occurred. An interviewee described how, in this case, several members responded with "a whole host of stuff" including directly confronting the individual to make clear that:

“you're an extremist, don't worm your way back into the community, you're known for what you do" (0003)

This, and several similar episodes, exemplify how communities can organically mobilise and organise to oppose extremist influencing efforts. A different example was where a community organisation found that, when members of the local community had travelled to Syria and other countries, young people would subsequently talk about travelling themselves. In response, the organisation focused on challenging and disproving the principles behind the propaganda the young people had seen, in a very frank and direct way:

"if they talk about it, we let them know that that person's more than likely not gonna come back" (040)

The next step was to counter the ideals used to persuade them to travel:

We'll break it down with them and explain to them how they were vulnerable ... how they got groomed ... and we show people videos of how ISIS treat people, and 'well is this how you expect to be treated as a woman?' ... Once you're there, they're not letting you out. (040)

Further tactics involved playing phone calls from people who want to, but cannot, get home to help convey the enormity of a decision to travel. Young women were also presented with the realities of being enslaved, and being sold and re-sold to numerous husbands. These examples capture some of the ways in which Prevent interventions can be delivered post- as well as preevent.

\subsection{COUNTER-GOVERNANCE}

The empirical data reported below show such interventions were not unproblematic, nor did they go unchallenged. As rehearsed in the opening to this paper, negative perceptions of Prevent and its implementation can be helpfully viewed through the lens of Bloomfield's (2013) formulation of counter-governance. Focusing upon corporate life and regulation, he identifies multiple 'pathologies' of governance that can induce a failure of a corporation to 
achieve its aims. Ultimately however, how he constructs this idea is both helpful and limiting. For whilst, counter-governance is instructive in highlighting the importance of attending to instances when governance does not work as intended and condenses such issues into a useful framing, Bloomfield's depiction focuses only upon fairly gross instances of governance failure. Thus, it certainly does not encompass the far more subtle kinds of contest and friction that Bevir $(2010 ; 2016)$ identifies as integral to the processes of everyday social organisation - what he labels 'resistance all the way down'.

In an effort to interpret and make sense of the empirical data underpinning this analysis, the article appropriates several features of Bloomfield's counter-governance concept and rearticulates it in dialogue with Bevir's notion of resistance. Elements of these two theoretical resources are amalgamated to document and describe the variety of frictions, resistances and contests that are an integral feature of delivering a complex policy intervention such as Prevent. Especially in a post-attack situation, there are multiple conflicting beliefs, meanings and interpretations constructed by members of different groups, which connect with complex arrays of intentionally and unintentionally generated formal and informal practices. Framed in this way, two principal configurations of counter-governance are delineated. 'Strategic countergovernance' is mainly concerned with Prevent as a set of ideas and normative judgements. Whereas, 'tactical counter-governance' attends to issues associated with practical delivery.

\subsubsection{Strategic counter-governance}

Interviewees recounted a series of carefully constructed arguments and criticisms that impacted upon the conduct of their work as Prevent practitioners. These focused upon: the key tenets of Prevent policy as a concept and brand; issues with formal Prevent intervention work (e.g. the 'Channel' de-radicalisation programme); and less formal, community interactions taking place around Prevent issues (e.g. dealing with early signs of radicalisation).

The allegation and assertion that Prevent is a 'toxic brand' is now well established and routinely invoked by its critics. One consequence of this was that it quite easily gained purchase and traction within a community:

"It's just like me and you meeting in the community and I said to you 'ohhh don't you know, don't pay attention to Prevent, it's spying, it's something', but you haven't really checked that, I've just told you that, and someone else has told me that, so nobody has bothered to go and visit a Prevent project that's working" (040)

The sentiment that criticism could be rebutted by visiting a 'project that's working' was commonplace. Moreover, it probably underplayed how such community concerns were undergirded by a lack of trust among some segments of the public about government and public services more generally. For instance, one interviewee described how, at public events, she was frequently asked:

$$
\text { "which side of Prevent are you on?" (037) }
$$

She was shocked that even though it is now "10 years down the line" from the instigation of Prevent, such viewpoints are a recurring refrain. The assertion that there are different 'sides' to be adopted evidences how it remains contested as a policy construct. 
Significantly, this recognition that there are different constructions of Prevent and what it should be, were not just externally generated, but occurred within the policy community also and were reflected in shifts in orientation:

"It was going down the ideological route, the theology, and that caused more division than it helped, because no one could agree"(0004)

This interviewee felt the shift to a more theological focus had actually created more confusion, preferring the previous approach that had pivoted around community cohesion and associated interventions. But more telling, is the acknowledgement that there are differing interpretations of Prevent amongst policy developers and deliverers, and active contests between them - 'what works' is not a settled question in this domain.

In seeking to explain how and why some of the more strategic critiques of Prevent have travelled and gained sustained traction, a number of interviewees attributed significant influence having been achieved by campaigning organisations that had performed a 'moral entrepreneurship' role:

"They came to us and said 'we don't have an issue with what you're doing, we just don't want you to take money off the government to do it" (040)

Another respondent recalled how they had written a news article concerning their work, with the result that:

"Immediately I had people from $C A G E^{2}$ and others having a go at me, and suddenly I found myself in the middle of Daesh propaganda" (039).

Ongoing attempts to develop and deliver Prevent are taking place in the middle of this battle of ideas. Another interviewee also discussed frustrations with people criticising their work, whilst offering no viable alternative.

At around the time these data were collected, the Home Affairs Select Committee had recently published a report of its inquiry into Prevent that had sought to engage with several of the critiques rehearsed above. A key recommendation made was to re-brand Prevent as 'Engage'. This was roundly dismissed as meaningless and ineffective:

"I certainly don't believe in the Select Committee saying it should be called 'Engage' ... engagement means nothing ... 'cause you can engage with Anjem Choudary” (038)

There was a feeling that changing the name would imply any work done previously "hasn't succeeded, when we know it has" (039). A number of interviewees also foresaw negative impacts following any name change:

"you're just setting up the new brand to fail and admit failure ... What you're saying is not only did that fail, but this new brand you've called it something else and we know it's the same" (0005)

\footnotetext{
${ }^{2}$ CAGE describe themselves as an independent organization 'striving for a world free of injustice and oppression'.
} 
"What would happen is the people who are against it will ... start on that new name ... I think it would disempower us workers on the ground by changing the name, because it'll make people feel like you know, that wasn't quite right'"(040)

If 're-branding' is rejected as a viable response to offset the challenges practitioners' work is subject too, some of Prevent's problems were attributed by respondents to a general failure to counter and argue against some of the more critical narratives propagated. Indeed, there was a noticeable trend over the course of 2017 for a change in the posture of government ministers and senior police in terms of their willingness to respond with assertive public statements, whenever criticisms of Prevent obtained publicity.

\subsubsection{Tactical counter-governance}

Tactical counter-governance is similar to its more strategic counterpart in that it aims to undermine or constrain Prevent's operational implementation. Where they differ however, is that strategic arguments tend to be quite detailed and structured, and often originate from more 'expert' sources - e.g. a 'human rights' organisation, or a 'political leader'. Instances of tactical counter-governance, on the other hand, tend to be briefer and less structured, or expert. They frequently appear to be triggered by high-profile events such as terror attacks and propagated by a wider variety of sources.

Although both types of counter-governance are often enacted online, a particularly high volume of instances of tactical counter-governance were detected on social media following the 2017 terror attacks. The data indicate this was part of a backlash response directed at government agencies and police when they are perceived to have failed in their duties to protect the public from harm. Several examples from 2017 show how this tactical inflection of countergovernance works. Cases include: the response to the statement of Assistant Commissioner Mark Rowley (UK national lead for CT policing) following the Westminster Bridge attack; the tenor of the response to the identifications of perpetrators Salman Abedi and Khuram Butt (who were known to authorities); and the misidentification of Abu Izzadeen as the Westminster attacker.

The key point is that, even in times of crisis, people will readily position themselves against the authorities, opposing and subverting the work being done by them. The oppositions found often call the authorities' actions and/or motives into question, or directly blame them for the relevant attack. These strategies were clearly evident following a public statement from AC Rowley, shortly after the Westminster attack, where he commented that:

"we must recognise now that our Muslim communities will feel anxious at this time given the past behaviour of the extreme right wing and we will continue to work with all community leaders in the coming days"

Although this was part of a much longer and detailed statement, this specific remark generated many negative reactions on social media. For example:

“I'm just gobsmacked by Mark Rowley's comments about right wing groups. How about denouncing violent Islamism? Let's start there!!” (22 March 2017, 22:45) 
Such reactions constitute tactical counter-governance in that they actively tried to challenge and contest Rowley's narrative and his authority. They shifted attention away from other elements of the statement as well as the pressing terror threat, instead focusing on one comment. These tactical counter-governance examples emerged mostly on Twitter, but there were also some on Facebook. His senior position in counter-terrorism policing cast him as the embodiment of state authority, and he was subject to considerable scrutiny in the following days.

On the $24^{\text {th }}$ of March, a manufactured meme began circulating, particularly amongst far rightwing thought communities on social media. This included a picture of Rowley, the comment from his statement, and a new message attached to it:

No mention or concern of the English community feeling anxious concerning Muslim terrorism and a prime example of liberalism that is killing England.

Although this did not really evolve the narrative, the new memetic format made the message much easier to share and repost online. When sharing the meme, some users also added their own comments, for example “@metpoliceuk do not give a stiff about the UK nationals" and "Stop appeasing and start acting". Others contributing to the counter-governance movement did so by calling Mark Rowley "a traitor" and his actions treasonous. The meme and narrative were used to mock the police, allege that they cannot do their job properly and infer that they do not care about British people:

Fuck them and fuck you Mr Rowley! What about us ........ THE BRITS? The people you promised to protect and serve!! (24 March 2017, 09:44)

This highly visceral example of counter-governance, seemingly facilitated by the social dynamics of online communication, challenged the police's authority and power, seeking to create the illusion of incompetence.

\subsection{3 'Failure to Protect'}

Instances of tactical counter-governance were also occasioned where allegations that the terrorist perpetrators were 'known' to the authorities in some way and had even been subject to Prevent interventions. When this occurred, it was used to fashion a narrative of incompetence and inaction by police and authorities, who were almost deemed accountable for the attacks. In essence, they posited that attacks could be prevented if authorities 'did their jobs properly'. As with the reposts to Mark Rowley, these criticisms were aimed at undermining the authority of Prevent policy, the government and police.

The misidentification of Abu Izzadeen as the Westminster attacker and the public responses to the (accurate) identifications of Salman Abedi and Khuram Butt as attackers are examples of this 'known nominals' issue. Of note, is that although Abu Izzadeen's identification by people on social media and by the mainstream media was a mistake, the rumour emerged and was shared widely precisely because it resonated with established counter-governance narratives.

Salman Abedi (Manchester bomber) and Khuram Butt (London Bridge attacker) were both accurately identified in the days following their respective attacks. It transpired they were both assessed by the authorities as potential threats. Abedi was born in the UK to Libyan parents. He had recently returned from a trip to Libya at the time of the attack, and it seems he may 
have also travelled to Syria. He was known to MI5, though he was not under active investigation. Khuram Butt was born in Pakistan, but raised in the UK. He had appeared on a television documentary around a year prior to the attack he and two others carried out in London. The documentary showed him openly mixing and praying with known extremists and associates of the proscribed group, al-Muhajiroun. Due to reports from concerned neighbours and his connections with al-Muhajiroun, Butt had been a "subject of interest" for the security services at the time of the attack. In both cases, tactical counter-governance emerged centring on the fact that the authorities knew the men, yet failed to prevent their attacks.

In Abedi's case, his family history and recent travel to the Middle East sparked much frustrated negative commentary. These frustrations inflected public criticisms made about the approach of police, government and security services:

police \& security services missed five opportunities over five years to stop Salman Abedi from carrying out his deadly terror attack. (26 May 2017, 00:42)

@.AmberRuddHR should resign for failing to prevent the \#ManchesterAttack, because she was aware Salman Abedi posed a threat to public safety. (26 May 2017, 00:48)

Citing the number of missed opportunities, blaming the authorities for the attack and calling for resignations, was a typical method of contesting the authorities' competence in relation to the Abedi episode.

Similar instances of counter-governance also emerged in response to Khuram Butt's identification. His appearance in a Channel 4 documentary (which was openly available at the time of the attack) was central to many arguments. Lack of action by authorities following its broadcast was considered a major failing:

The new normal is London killer Khuram Butt on telly in C4 doc last year posing as jihadi with black flag. Nothing 2 b alarmed by obviously (6 June 2017, 00:03)

Referring to the documentary was a way to justify counter-governance and anger because members of the public could see the 'evidence' for themselves. Butt being open about his extremist views on national television was considered a joke in itself, but the lack of intervention from authorities following the broadcast was seen as catastrophic.

Similar in many ways, was the rumour that well-known hate preacher Abu Izzadeen was the Westminster attacker. The rumour was shared widely on social media (Twitter and Facebook) and even made it into mainstream media via a Channel 4 news broadcast. It appears that his physical resemblance to the real attacker (Khalid Masood) may have caused the confusion. Until the rumour was dispelled it constituted another example of counter-governance: the rumour travelled (being reposted and shared extensively across social media) precisely because people sought to blame the authorities in the aftermath of the attack. Izzadeen has been affiliated with the banned extremist group al-Muhajiroun and a close associate of Anjem Choudary for around 20 years. He is well-known for his views and has been the subject of multiple media stories over the years. He has been imprisoned several times for various offences, including inflammatory speeches at a mosque. As a result, he has become notorious and the target of far-right criticism. If he were the attacker, it would have been an exceptional failing on the part of the authorities. This goes some way to explaining the tactical countergovernance that emerged. 
The rhetorical devices drawn upon in the Izzadeen case were similar to those described in relation to Abedi and Butt. While the rumour was still in circulation, authorities were again blamed for the attack and some police and government actors were told they should resign because of their assumed failure to stop a prolific individual. The following tweets illustrate how users attempted to undermine and oppose the authorities:

If it's true Abu Izzadeen is the terrorist .. met chief of police and amber Rudd need to resign IMMEDIATELY! -2\#bloodonyourhands \#Westminster (22 March 2017, 18:45)

If the \#Westminster attacker is indeed Abu Izzadeen, the UK counter terrorist unit may as well pack up and go home. (22 March 2017, 18:53)

Twitter data shows heavy far-right influence in this case, as the most re-tweeted posts came from far-right or right-wing accounts. Their significant involvement in counter-governance is unsurprising given their existing conflict with Izzadeen. When the true identity of the attacker was later revealed, there was a slight shift in the narrative, though many of the antagonistic and Islamophobic sentiments were sustained.

A key argument being pursued here then, is that the communication of these 'soft facts' in the wake of these incidents amplifies the harm the events ultimately induce. Given the influence of the far-right, one proxy measure for such harm could be levels of hate crime experienced. Examining data for recorded hate crime during the aftermath of each of the three Islamistinspired attacks, it is evident how there was a significant increase in reported hate crime nationally. The exception to this pattern was the Finsbury Park incident, which was the only attack committed by an individual with extreme far-right sympathies (Figure 2).

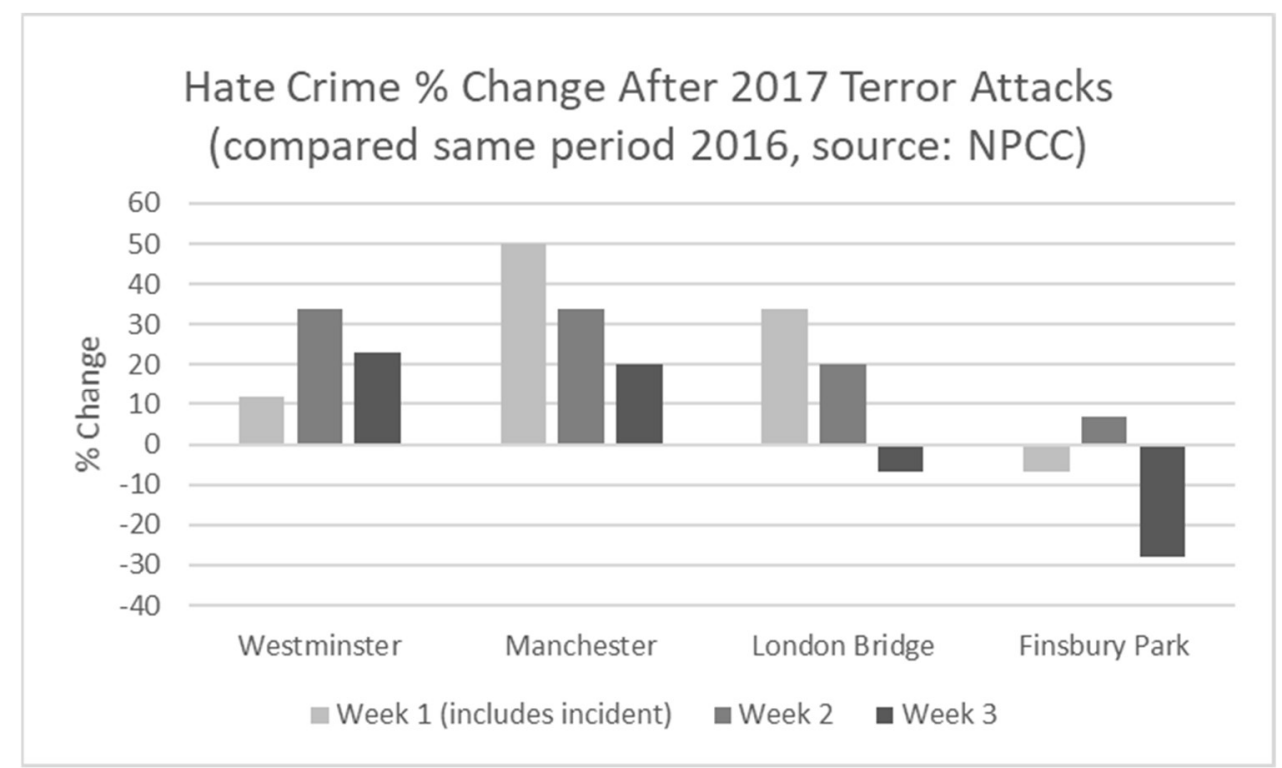

FIGURE 2: Nationally recorded hate crime in the three weeks after the 2017 UK terror attacks, compared with the same period in 2016 (UK National Police Chiefs Council). 
In addition to this far-right dimension, some foreign political influence from accounts associated with the now infamous Internet Research Agency in Russia was detected (see below). Although this digital influence engineering was present across all the 2017 attacks, the Abu Izzadeen case is particularly interesting, as the Russian accounts were directly involved in trying to mobilise counter-governance. For example:

Here's suspect Abu Izzadeen urging British shoppers to convert to Islam, right on the street of \#London!... https://t.co/DXEebwgZ0T (22 March 2017, 19:19)

Several known Russian accounts (Pamela_Moore13, SouthLoneStar and TEN_GOP) used tweets about Izzadeen to heighten tensions around freedom of speech laws, Muslims and street preaching. But where the other forms of counter-governance documented herein were primarily domestically oriented, the involvement of these Russian accounts in all of the 2017 terror attacks constitutes a form infused with geo-political strategizing.

\subsection{GEO-POLITICAL COUNTER-GOVERNANCE}

Geo-political counter-governance is characterised by other nation states attempting to amplify the domestic harms felt by communities following terror attacks. There is robust evidence that under conditions of crisis and conflict - such as in the aftermath of terrorist violence - people become more 'influenceable'. This goes some way to explaining the evidence of foreign influence following the four 2017 attacks. Involvement in this form of counter-governance is not limited to Russian agents however, with North American and European right-wing groups also contributing.

In 2017, several sources (including the Russian Magazine РБК and investigations by the US Senate) evidenced that some Facebook and Twitter accounts were fronts for organisations such as the St Petersburg based Internet Research Agency. Forty-seven of these Russian 'spoof' accounts ( 8 of which were highly active) were identified as having made communicative interventions following each of the UK terror attacks (Innes et al., 2017). Analysis further indicates that at least one account was sending inflammatory messages within 15 minutes of the Manchester and London Bridge attacks. Indeed, several accounts were framed as 'breaking news' sources. Rapidly responding to interpret and frame the definition of situations is important in being able to shape public understanding. Sowing seeds of antagonism and anxiety at the earliest possible opportunity during the course of an incident increases the capacity for influence.

Considerable support for some of these messages occurred on social media. For example, the following was sent less than one hour after the Manchester attack and was retweeted 3606 times:

Another day, another Muslim terrorist attack. RETWEET if you think that Islam needs to be banned RIGHT NOW! Manches...(22 May 2017,22:22) (@TEN_GOP)

Some of the spoofed accounts under Russian direction and control had large numbers of followers. For example, on the 26 ${ }^{\text {th }}$ June 2017: @TEN_GOP (right-wing, anti-Islam stance) had around 127,000 followers; @Crystal1Johnson (adopting a black rights stance) had nearly 46,000 followers; and @SouthLoneStar (again right-wing) had almost 54,000 followers. This is an indicator of their ability to resonate with audiences. The accounts were being used as 
'sock puppets' mimicking particular ideological positions: the users behind them consistently projected and propagated messages that were consistent with the adopted account identities. This was one of the most interesting techniques of influence used by these accounts. In one example, the image of a Muslim woman on Westminster Bridge walking past a victim being treated for their injuries became an infamous internet meme. In the dataset, it can be observed how differently positioned Russian faked accounts authored contrasting responses to it. From @TEN_GOP:

She is being judged for her own actions \& lack of sympathy. Would you just walk by? Or offer help?

And from@Crystal1Johnson:

so this is how a world with glasses of hate look like - poor woman, being judged only by her clothes.

There were multiple further examples of this behaviour in the data. The goal of these actions appears to be the amplification of social tension and thus the public harms of the terror attacks, in support of Russia's wider geopolitical strategy.

\subsection{CONCLUSION}

At its core, this article has set out four principal claims. First, it has mapped out several forms of counter-governance to the design and delivery of the government's Prevent counterterrorism strategy. Counter-governance is deployed as a master-concept to label various instances of opposition, resistance, friction and contestation. A key thrust of the analysis has been to differentiate between how these forms of counter-governance manifest in 'ordinary time' and following terrorist attacks. It is our assertion that studying key moments can be important in understanding the causes and consequences of specific counter-governance movements. In respect of Prevent and counter-terrorism policy specifically, the aftermaths of terrorist attacks are especially insightful as almost paradoxically they simultaneously evidence need and failure.

Developing the preceding point, particular policy implications flow from this approach. These can be summarized as establishing a space for what might be termed 'post-event Prevent'. In its current form, and resonating with wider currents in contemporary governance rationalities. (Garland, 2001), Prevent is almost entirely conceived in terms of upstream interventions that seek to anticipate, and pre-empt, risks and threats of terrorist violence. However, there seems an equally important requirement to be able to manage harms induced by such forms of violence. Situated in a period where there is a widespread consensus amongst senior police and security officials that it will not be possible to prevent all future plots, developing a capacity and capability to better mitigate harms and societal impacts possesses considerable public value.

The third claim concerns issues of methodology and how social media analytics occasion new ways of seeing complex phenomena such as social reactions to terrorism. The blend of content detail, ability to scale and the streaming quality of the data, opens up new opportunities for generating innovative insights and evidence (Benkler et al., 2018). Germane to the particular empirical focus of this article, there is a transformative potential for how processes of social 
reaction to major public events and crises are studied. This is especially important given how what happens online increasingly influences offline behaviours, and vice versa. With this in mind, a significant innovation in the preceding discussion has been the blending of qualitative interview and digital data, to map out some of the complex online and offline interactions that arise in defining post-attack situations. For emulsified in the routines, rituals and rhythms of social life, social media are increasingly influential 'instruments of perception' shaping which problems are collectively focused upon, and which neglected in the ordering of reality (Amoore and Piotukh, 2015).

The final main claim mounted by this paper is more conceptual and concerns how the idea of counter-governance speaks to the literatures on 'decentered regulation' and 'decentered governance'. Albeit oriented to different epistemic communities and substantive domains, scholars such as Black (2001) and Bevir (2016) have constructed diagnoses of trends in the logics and rationalities of governance that possess more than a passing resemblance to each other. What this analysis captures is how these arrangements are not untrammeled and unproblematic. Rather, in a media saturated ecology of pluralistic and interpolated collective and social identities, the translation of policy into practice requires navigating complex resistances, frictions and oppositions. Re-framing Bloomfield's (2013) concept of countergovernance to incorporate Bevir's $(2010 ; 2016)$ insights into the complexities around democracy and resistance is important in understanding this ecology. Significantly, these conflicts and frictions should not be cast as external to policy and practice. Rather, in terms of our conceptual treatments of contentious policy objects, processes of resistance and contestation, need to be understood as integrated into their essential forms. For even in the aftermath of terrorist violence, at moments of profound social urgency and emergency, these processes can still be observed, suggesting how important and integral they are in configuring the contemporary ordering of social reality.

\section{REFERENCES}

Amoore, L., Piotukh, V., 2015. Life beyond big data governing with little analytics. Economy and Society. 44/3, 341-366.

Ashworth, A., Zedner, L., 2014. Preventive Justice. Oxford, Oxford University Press.

Benkler, Y., Faris, R., Roberts, H., 2018. Network Propaganda: Manipulation, Disinformation, and Radicalization in American Politics. New York, Oxford University Press.

Bevir, M., 2010. Democratic Governance. Princeton, N.J.; Woodstock: Princeton University Press.

Bevir, M., 2016. Decentring security governance. Global Crime 17(3-4), 227-39.

Birt, Y., 2008. Governing Muslims after 9/11, in: Sayyid, S., Vakil, A. (Eds), Thinking through Islamophobia: Symposium Papers. Leeds, Centre for Ethnicity and Racism Studies, pp.26-29.

Black, J., 2001. Decentring regulation: Understanding the role of regulation and self-regulation in a 'post-regulatory' world. Current Legal Problems, 54(1), 103-46. 
Bloomfield, S., 2013. Theory and Practice of Corporate Governance. Cambridge, Cambridge University Press.

Garland, D., 2001. The Culture of Control. New York, Oxford University Press.

Gonzalez-Bailon, S., 2017. Decoding the Social World. Cambridge, Ma., MIT Press.

Heath-Kelly, C., 2013. Counter-Terrorism and the Counterfactual: Producing the 'Radicalisation' Discourse and the UK PREVENT Strategy. The British J. of Politics and International Relations, 15/3, 394-415.

H.M. Government, 2009. Pursue, Prevent, Protect, Prepare: The United Kingdom's Strategy for Countering International Terrorism. London, Crown Stationery Office.

H.M. Government, 2011. Prevent Strategy. London, Crown Stationery Office.

H.M. Government, 2015. Counter Extremism Strategy. London, Crown Stationery Office.

Innes, M., Roberts, C., Innes, H., 2011. Assessing the Effects of Prevent Policing. London, ACPO.

Innes, M., 2014. Signal Crimes: Social Reactions to Crime, Disorder and Control. Oxford, Oxford University Press

Innes, M., Roberts, C., Lowe, T., 2017. A disruptive influence: Prevent-ing problems and countering violent extremism policy in practice. Law and Society Review.

Kundani, A., 2009. Spooked: How Not to Prevent Violent Extremism. London, Institute of Race Relations.

Lakhani, S., 2012. Preventing Violent Extremism: Perceptions of Policy from Grassroots and Communities. Howard J. of Criminal Justice, 51, 190-206.

O'Toole, T., Meer, N., DeHanas, D., Jones, S., Modood, T., 2016. Governing through Prevent? Regulation and contested practice in state-Muslim engagement. Sociology, 50(1), 160-177.

Pantazis, C., Pemberton, S., 2009. From the 'Old' to the 'New' Suspect Community Examining the Impacts of Recent UK Counter-Terrorist Legislation. British J. of Criminology, 49, 64666.

Salganik, M., 2017. Bit by Bit. Princeton, Princeton University Press.

Walker, C., McKay, S., 2015. Community Surveillance and Terrorism, in: Pearse, J. (Ed.), Investigating Terrorism: Current Political, Legal and Psychological Issues. Chichester, WileyBlackwell. 